\title{
SYNERGISTIC EFFECTS OF FIBRE DEBONDING AND FRACTURING ON VIBRATION DAMPING IN FIBRE-REINFORCED CERAMIC-MATRIX COMPOSITES
}

\author{
LONGBIAO LI \\ College of Civil Aviation, Nanjing University of Aeronautics and Astronautics, \\ No.29 Yudao St., Nanjing 210016, PR China \\ \#E-mail: 1lb451@nuaa.edu.cn
}

Submitted February 26, 2020; accepted May 7, 2020

\begin{abstract}
Keywords: Ceramic-matrix composites (CMCs), Damping, Matrix cracking, Interface debonding, Fibre fracture
In this paper, the synergistic effects of fibre debonding and fracturing on vibration damping in fibre-reinforced ceramicmatrix composites (CMCs) is investigated. The relationships between the damping of the CMCs, the damping of the fibre and the matrix, the damping caused by the frictional slip between the fibre and the matrix, and the fibre debonding and fracturing are established. The effects of the fibre volume, matrix crack spacing, interface shear stress, interface debonding energy, fibre strength and fibre Weibull modulus on the damping of the CMCs, the interface debonding and slip between the fibre and the matrix, and the fibre broken fraction are analysed. The damping of the unidirectional CMCs with and without considering the fibre failure is discussed. The experimental damping of a $2 \mathrm{D} \mathrm{C/SiC} \mathrm{composite} \mathrm{is} \mathrm{predicted} \mathrm{using} \mathrm{the} \mathrm{present} \mathrm{analysis.} \mathrm{When}$ the fibre volume increases, the composite damping decreases, due to the decrease in the interface debonding and slip length and the broken fibre fraction. Considering the fibre failure, the composite damping decreases, due to the increase in the fibre broken fraction. When the fibre strength and fibre Weibull modulus increase, the composite damping increases, due to the decrease of the interface debonding length, interface slip length, and broken fibre fraction.
\end{abstract}

\section{INTRODUCTION}

Ceramic matrix composites (CMCs) have the advantages of low density, high specific strength, high specific modulus, and high temperature resistance, etc., and are the candidate materials for the hot section components of aerospace vehicles, high thrust-to-weight-ratio aeroengines, satellite attitude control engines, ramjets, and thermal protection systems, and so on [1, 2, 3, 4]. However, in the above applications, vibration and noise problems exist. The failure analysis of rockets and satellites shows that about two-thirds of the failures are related to vibration and noise, leading to reduced operational control accuracy, structural fatigue damage, and a shortened safety life [5]. Therefore, studying the damping performance of CMCs and improving their reliability in the service environment of vibration and noise is an important guarantee for the safe service of CMCs in various fields.

Compared with metals and alloys, CMCs have many unique damping mechanisms due to the internal structure and complex damage mechanisms [6]. Birman and Byrd [7] investigated the effect of matrix cracks on the damping in unidirectional and cross-ply CMCs at room temperature. The energy dissipation in unidirectional CMCs with bridging matrix cracks were considered. Sato et al. [8] compared the internal friction and elastic modulus of $\mathrm{SiC} / \mathrm{SiC}$ composites fabricated by polymer impregnation and pyrolysis (PIP), hot press (HP) and chemical vapour infiltration (CVI). The internal friction of a CVI $\mathrm{SiC} / \mathrm{SiC}$ composite was found to be largely affected by the property of the fibre, and the microstructure of the matrix. Wang et al. [9] investigated the effects of a coating, testing the frequency and thermal treatment on the damping capacity of a $2 \mathrm{D} \mathrm{C} / \mathrm{SiC}$ composite fabricated by CVI. It was found that the damping mechanism of the $\mathrm{CVI} \mathrm{C/SiC}$ composite includes microcracking propagation, interface debonding, and damping of the reinforcement fibre and interphase. Zhang et al. [10] investigated the effect of the interphase thickness on the damping behaviour of a $2 \mathrm{D} \mathrm{C} / \mathrm{SiC}$ composite from room temperature to $400{ }^{\circ} \mathrm{C}$ in an air atmosphere. The damping increased gradually with the temperature and then decreased after a damping peak appeared in the temperature range of 250 to $300^{\circ} \mathrm{C}$. The damping capacity and peak value decreased with an increasing frequency and was accompanied with a shift of the damping peak towards lower temperatures. With an increasing $\mathrm{PyC}$ interphase thickness in the range of $90-296 \mathrm{~nm}$, the damping peak of the composite increased and the temperature corresponding to the peak shifted to the lower temperature. Hong et al. [11] investigated the relationship between the oxidation and the internal friction of a $\mathrm{C} / \mathrm{SiC}$ composite at $1300{ }^{\circ} \mathrm{C}$ in 
an air atmosphere. The internal frictional behaviour of the $\mathrm{C} / \mathrm{SiC}$ composite is controlled by the oxidation of the PyC interphase. Li [12] investigated the natural frequency and damage of CMCs, and established the relationship between the natural frequency and the internal damages. Li [13-19] investigated matrix cracking, hysteresis loops, damage evolution and life prediction of different fibre-reinforced CMCs. However, in the research mentioned above, the effect of interface debonding on the vibration damping behaviour of CMCs has not been investigated.

In this paper, the synergistic effects of fibre debonding and fracturing on the vibration damping in fibrereinforced CMCs is investigated. The relationships between the damping of the CMCs, the damping of fibre and the matrix, the damping caused by the frictional slip between the fibre and the matrix, and the fibre debonding and fracturing are established. The effects of the fibre volume, matrix crack spacing, interface shear stress, interface debonding energy, fibre strength and fibre Weibull modulus on the damping of the CMCs, the interface debonding and the slip between the fibre and the matrix, and the fibre broken fraction are analysed. The damping of unidirectional CMCs with and without considering the fibre failure is discussed. The experimental damping of a $2 \mathrm{D} \mathrm{C} / \mathrm{SiC}$ composite is predicted using the present analysis.

\section{THEORETICAL}

The loss factor of the material $\eta$ can be determined using the following equation.

$$
\eta=\frac{U_{\mathrm{d}}}{2 \pi U}
$$

where $U_{d}$ is the density of the energy dissipated per cycle of motion (energy per unit volume per cycle) and $U$ is the maximum strain energy density during the cycle.

The relationship between the specific damping capacity $(\psi)$, the logarithmic decrement $(\delta)$, and the damping ratio $(\zeta)$ can be determined using the following equation.

$$
\psi=2 \delta=4 \pi \zeta=2 \pi \eta
$$

Under vibration of CMCs, the composite applied stress is given by:

$$
\sigma_{\mathrm{c}}=\sigma(1+\sin \omega t)
$$

where $\omega$ is the vibration frequency.

\section{Damping in intact CMCs}

The loss factor $\left(\eta_{\mathrm{x}}\right)$ for a unidirectional composite without damage subject to axial loading can be determined using the following equation.

$$
\eta_{x}=\frac{E_{\mathrm{f}} V_{\mathrm{f}} \eta_{\mathrm{f}}+E_{\mathrm{m}} V_{\mathrm{m}} \eta_{\mathrm{m}}}{E_{\mathrm{f}} V_{\mathrm{f}}+E_{\mathrm{m}} V_{\mathrm{m}}}
$$

where $\eta_{\mathrm{f}}$ and $\eta_{\mathrm{m}}$ denote the loss factors for the fibre and matrix materials, respectively. When matrix cracking and interface debonding occur, the effective matrix elastic modulus $\left(\bar{E}_{\mathrm{m}}\right)$ is determined using the following Equation.

$$
\bar{E}_{\mathrm{m}}=\frac{\tau_{\mathrm{i}}}{V_{\mathrm{m}}} \cdot \frac{1}{\frac{\tau_{\mathrm{i}}}{E_{\mathrm{c}}}+\frac{r_{\mathrm{f}}}{4 l_{\mathrm{c}}} \cdot \frac{\Delta \sigma}{E_{\mathrm{f}}} \cdot\left(\frac{V_{\mathrm{m}} E_{\mathrm{m}}}{V_{\mathrm{f}} E_{\mathrm{c}}}\right)^{2}}-\frac{V_{\mathrm{f}} E_{\mathrm{f}}}{V_{\mathrm{m}}}
$$

where $\tau_{i}$ denotes the interface shear stress; $r_{f}$ denotes the fibre radius; $V_{\mathrm{f}}$ and $V_{\mathrm{m}}$ denote the fibre and matrix volume fraction, respectively; $E_{\mathrm{f}}$ and $E_{\mathrm{m}}$ denote the fibre and matrix elastic modulus, respectively; $E_{\mathrm{c}}$ denotes the longitudinal modulus of the intact composite material; $l_{\mathrm{c}}$ denotes the matrix crack spacing; and $\Delta \sigma$ denotes the range of the applied stress $(\Delta \sigma=2 \sigma)$.

\section{Damping in damaged CMCs}

When matrix cracking and interface debonding occur in CMCs, the loss factor $\left(\eta_{\mathrm{y}}\right)$ can be determined using the following equation.

$$
\eta_{y}=\frac{U_{\mathrm{d}}}{2 \pi U}
$$

where

$$
\begin{gathered}
U_{\mathrm{d}}=U_{\mathrm{d} \_ \text {unloading }}+U_{\mathrm{d} \_ \text {reloading }} \\
U=U_{\mathrm{f}}+U_{\mathrm{m}}
\end{gathered}
$$

where $U_{\mathrm{d} \text { unloading }}$ and $U_{\mathrm{d} \text { reloading }}$ denote the dissipated energy upon unloading and reloading, respectively; and $U_{\mathrm{f}}$ and $U_{\mathrm{m}}$ denote the fibre and matrix strain energy, respectively.

$$
\begin{gathered}
U_{\mathrm{d} \_ \text {unloading }}=2 \pi r_{\mathrm{f}} \frac{\tau_{\mathrm{i}}}{E_{\mathrm{f}}}\left[\left(\Phi-\Phi_{\mathrm{U}}\right) l_{\mathrm{y}}^{2}-\frac{8}{3} \frac{E_{\mathrm{c}} \tau_{\mathrm{i}}}{r_{\mathrm{f}} V_{\mathrm{m}} E_{\mathrm{m}}} l_{\mathrm{y}}^{3}\right] \\
U_{\mathrm{d} \_ \text {reloading }}=2 \pi r_{\mathrm{f}} \frac{\tau_{\mathrm{i}}}{E_{\mathrm{f}}}\left[\left(\Phi-\Phi_{\mathrm{R}}\right) l_{\mathrm{z}}^{2}-\frac{8}{3} \frac{E_{\mathrm{c}} \tau_{\mathrm{i}}}{r_{\mathrm{f}} V_{\mathrm{m}} E_{\mathrm{m}}} l_{\mathrm{z}}^{3}\right] \\
U_{\mathrm{f}}=\pi r_{\mathrm{f}}^{2}\left\{\frac{\Phi^{2}}{E_{\mathrm{f}}} l_{\mathrm{d}}-\frac{\tau_{\mathrm{f}} \Phi}{r_{\mathrm{f}} E_{\mathrm{f}}} l_{\mathrm{d}}^{2}+\frac{4}{3} \frac{\tau_{i}^{2}}{r_{\mathrm{f}}^{2} E_{\mathrm{f}}} l_{\mathrm{d}}^{3}+\frac{\sigma_{\mathrm{fo}}^{2}}{E_{\mathrm{f}}}\left(\frac{l_{\mathrm{c}}}{2}-l_{\mathrm{d}}\right)\right. \\
+2 \frac{r_{\mathrm{f}} \sigma_{\mathrm{fo}}}{\rho E_{\mathrm{f}}}\left(\Phi-\sigma_{\mathrm{fo}}-2 \frac{l_{\mathrm{d}}}{r_{\mathrm{f}}} \tau_{\mathrm{i}}\right)\left(1-\exp \left[-\rho \frac{l_{\mathrm{c}} / 2-l_{\mathrm{d}}}{r_{\mathrm{f}}}\right]\right) \\
\left.+\frac{r_{\mathrm{f}}}{2 \rho E_{\mathrm{f}}}\left(\Phi-\sigma_{\mathrm{fo}}-2 \frac{l_{\mathrm{d}}}{r_{\mathrm{f}}} \tau_{\mathrm{i}}\right)^{2}\left(1-\exp \left[-2 \rho \frac{l_{\mathrm{c}} / 2-l_{\mathrm{d}}}{r_{\mathrm{f}}}\right]\right)\right\}
\end{gathered}
$$

$$
\begin{aligned}
U_{\mathrm{m}} & =\pi r_{\mathrm{f}}^{2}\left\{\frac{V_{\mathrm{f}} \tau_{\mathrm{i}}}{r_{\mathrm{f}} V_{\mathrm{m}} E_{\mathrm{m}}} l_{\mathrm{d}}^{2}+\frac{\sigma_{\mathrm{mo}}^{2}}{E_{\mathrm{m}}}\left(\frac{l_{\mathrm{c}}}{2}-l_{\mathrm{d}}\right)\right. \\
& -2 \frac{r_{\mathrm{f}} V_{\mathrm{f}} \sigma_{\mathrm{mo}}}{\rho V_{\mathrm{m}} E_{\mathrm{m}}}\left[\Phi-\sigma_{\mathrm{fo}}-2 \tau_{\mathrm{i}} \frac{l_{\mathrm{d}}}{r_{\mathrm{f}}}\right]\left[1-\exp \left[-\frac{\rho\left(l_{\mathrm{c}} / 2-l_{\mathrm{d}}\right)}{r_{\mathrm{f}}}\right]\right] \\
& \left.+\frac{r_{\mathrm{f}} V_{\mathrm{f}}^{2}}{2 \rho V_{\mathrm{m}}^{2} E_{\mathrm{m}}}\left[\Phi-\sigma_{\mathrm{fo}}-2 \tau_{\mathrm{i}} \frac{l_{\mathrm{d}}}{r_{\mathrm{f}}}\right]^{2}\left[1-\exp \left[-2 \frac{\rho\left(l_{\mathrm{c}} / 2-l_{\mathrm{d}}\right)}{r_{\mathrm{f}}}\right]\right]\right\}
\end{aligned}
$$


where $l_{\mathrm{d}}$ denotes the interface debonding length; $l_{\mathrm{y}}$ and $l_{\mathrm{z}}$ denote the counter slip length upon unloading and the new slip length upon reloading, respectively; $\rho$ denotes the shear-lag model parameter; $\sigma_{\mathrm{fo}}$ and $\sigma_{\mathrm{mo}}$ denote the fibre and matrix axial stress in the interface bonding region, respectively.

$$
\begin{aligned}
& l_{\mathrm{d}}=\frac{r_{\mathrm{f}}}{2}\left(\frac{V_{\mathrm{m}} E_{\mathrm{m}}}{E_{\mathrm{c}} \tau_{i}} \Phi-\frac{1}{\rho}\right)- \\
& -\sqrt{\left(\frac{r_{\mathrm{f}}}{2 \rho}\right)^{2}-\frac{r_{\mathrm{f}}^{2} V_{\mathrm{f}} V_{\mathrm{m}} E_{\mathrm{f}} E_{\mathrm{m}} \Phi}{4 E_{\mathrm{c}}^{2} \tau_{\mathrm{i}}^{2}}\left(\Phi-\frac{\sigma}{V_{\mathrm{f}}}\right)+\frac{r_{\mathrm{f}} V_{\mathrm{m}} E_{\mathrm{m}} E_{\mathrm{f}}}{E_{\mathrm{c}} \tau_{\mathrm{i}}^{2}} \xi_{\mathrm{d}}}
\end{aligned}
$$

$$
\begin{aligned}
& l_{\mathrm{y}}=\frac{1}{2}\left\{l_{\mathrm{d}}-\left[\frac{r_{\mathrm{f}}}{2}\left(\frac{V_{\mathrm{m}} E_{\mathrm{m}}}{E_{\mathrm{c}} \tau_{\mathrm{i}}} \Phi_{\mathrm{U}}-\frac{1}{\rho}\right)-\right.\right. \\
& \left.\left.-\sqrt{\left(\frac{r_{\mathrm{f}}}{2 \rho}\right)^{2}-\frac{r_{\mathrm{f}}^{2} V_{\mathrm{f}} V_{\mathrm{m}} E_{\mathrm{f}} E_{\mathrm{m}} \Phi_{\mathrm{U}}}{4 E_{\mathrm{c}}^{2} \tau_{\mathrm{i}}^{2}}\left(\Phi_{\mathrm{U}}-\frac{\sigma}{V_{\mathrm{f}}}\right)+\frac{r_{\mathrm{f}} V_{\mathrm{m}} E_{\mathrm{m}} E_{\mathrm{f}}}{E_{\mathrm{c}} \tau_{\mathrm{i}}^{2}} \xi_{\mathrm{d}}}\right]\right\}
\end{aligned}
$$

$$
\begin{aligned}
& l_{\mathrm{z}}=l_{\mathrm{y}}-\frac{1}{2}\left\{l_{\mathrm{d}}-\left[\frac{r_{\mathrm{f}}}{2}\left(\frac{V_{\mathrm{m}} E_{\mathrm{m}}}{E_{\mathrm{c}} \tau_{\mathrm{i}}} \Phi_{\mathrm{R}}-\frac{1}{\rho}\right)-\right.\right. \\
& \left.\left.-\sqrt{\left(\frac{r_{\mathrm{f}}}{2 \rho}\right)^{2}-\frac{r_{\mathrm{f}}^{2} V_{\mathrm{f}} V_{\mathrm{m}} E_{\mathrm{f}} E_{\mathrm{m}} \Phi_{\mathrm{R}}}{4 E_{\mathrm{c}}^{2} \tau_{\mathrm{i}}^{2}}\left(\Phi_{\mathrm{R}}-\frac{\sigma}{V_{\mathrm{f}}}\right)+\frac{r_{\mathrm{f}} V_{\mathrm{m}} E_{\mathrm{m}} E_{\mathrm{f}}}{E_{\mathrm{c}} \tau_{\mathrm{i}}^{2}} \xi_{\mathrm{d}}}\right]\right\}
\end{aligned}
$$

$$
\frac{\sigma}{V_{\mathrm{f}}}=2 \Phi\left(\frac{\sigma_{\mathrm{c}}}{\Phi}\right)^{m_{\mathrm{f}}+1}\left\{\exp \left[-\left(\frac{\Phi-\Phi_{\mathrm{U}}}{2 \Phi}\right)\left(\frac{\Phi}{\sigma_{\mathrm{c}}}\right)^{m_{\mathrm{f}}+1}\right]-1+\frac{1}{2} P(\Phi)\right\}
$$

$$
\begin{aligned}
& \frac{\sigma}{V_{\mathrm{f}}}=2 \Phi\left(\frac{\sigma_{\mathrm{c}}}{\Phi}\right)^{m_{\mathrm{f}}+1}\left\{\exp \left[-\left(\frac{\Phi \mathrm{m}}{2 \Phi}\right)\left(\frac{\Phi}{\sigma_{\mathrm{c}}}\right)^{m_{\mathrm{f}}+1}\right]-\right. \\
& \left.-\exp \left[-\left(\frac{\Phi_{\mathrm{R}}-\Phi+\Phi_{\mathrm{m}}}{2 \Phi}\right)\left(\frac{\Phi}{\sigma_{\mathrm{c}}}\right)^{m_{\mathrm{f}}+1}\right]+\frac{1}{2} P(\Phi)\right\}
\end{aligned}
$$

$$
\begin{gathered}
\sigma_{\text {fo }}=\frac{E_{\mathrm{f}}}{E_{\mathrm{c}}} \sigma+E_{\mathrm{f}}\left(\alpha_{\mathrm{c}}-\alpha_{\mathrm{f}}\right) \Delta T \\
\sigma_{\mathrm{mo}}=\frac{E_{\mathrm{f}}}{E_{\mathrm{c}}} \sigma+E_{\mathrm{m}}\left(\alpha_{\mathrm{c}}-\alpha_{\mathrm{m}}\right) \Delta T
\end{gathered}
$$

where $\xi_{\mathrm{d}}$ denotes the interface debonding energy; $\alpha_{\mathrm{f}}, \alpha_{\mathrm{m}}$, and $\alpha_{\mathrm{c}}$ denote the fibre, matrix and composite thermal expansion coefficients, respectively; and $\Delta T$ denotes the temperature difference between the testing and fabricated temperature.

\section{RESULTS AND DISCUSSION}

The damping of CMCs with matrix cracking and interface debonding can be determined using the following equation.

$$
\eta_{\mathrm{c}}=\eta_{\mathrm{x}}+\eta_{\mathrm{y}}
$$

Birman and Byrd [7] investigated the effect of matrix cracks on damping in a unidirectional SiC/CAS composite. The material properties of the SiC/CAS composite are given by [7]: $E_{\mathrm{f}}=200 \mathrm{GPa}, E_{\mathrm{m}}=97 \mathrm{GPa}$, $V_{\mathrm{f}}=0.35, r_{\mathrm{f}}=8 \mu \mathrm{m}, \xi_{\mathrm{d}}=0.01 \mathrm{~J} \cdot \mathrm{m}^{-2}, \tau_{\mathrm{i}}=17 \mathrm{MPa}, l_{\mathrm{c}}=$ $=125 \mu \mathrm{m}, \eta_{\mathrm{f}}=0.002, \eta_{\mathrm{m}}=0.001, \alpha_{\mathrm{f}}=3.3 \times 10^{-6} /{ }^{\circ} \mathrm{C}$, $\alpha_{\mathrm{m}}=4.6 \times 10^{-6} /{ }^{\circ} \mathrm{C}, \Delta T=-1000{ }^{\circ} \mathrm{C}, \sigma_{\mathrm{c}}=2.0 \mathrm{GPa}, m_{\mathrm{f}}=3$. The effect of the fibre volume, matrix crack spacing, interface shear stress, interface debonding energy, fibre strength, and fibre Weibull modulus on the damping of the CMCs are analysed. The comparison analysis of the damping with and without considering the fibre failure is also discussed.

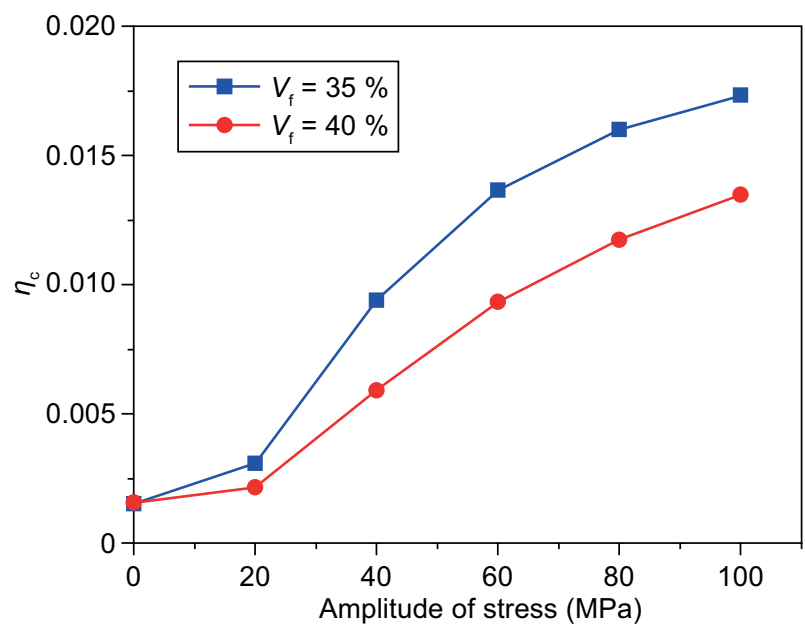

a)

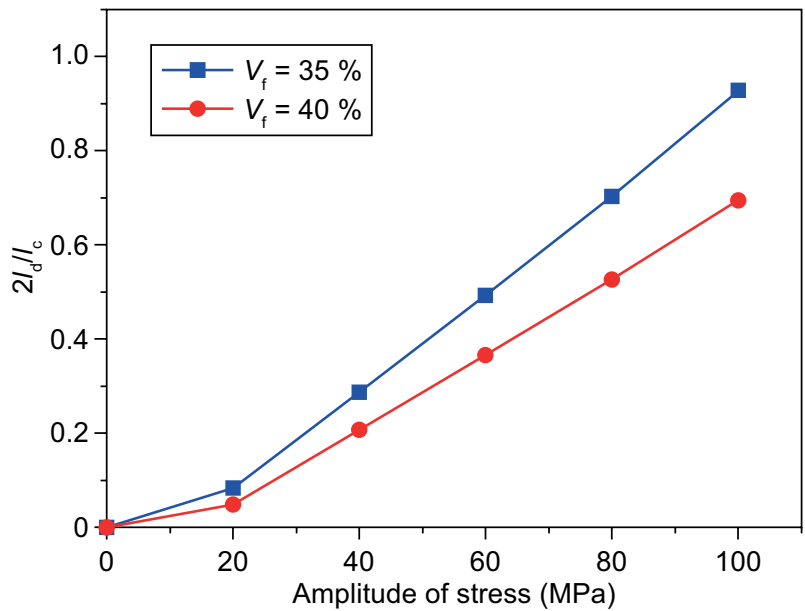

b)

Figure 1. The effect of the fibre volume (i.e., $V_{\mathrm{f}}=35$ and $40 \%$ ) on: a) the damping $\left(\eta_{\mathrm{c}}\right)$ versus the amplitude of the stress curves; b) the interface debonding length $\left(2 l_{\mathrm{d}} / l_{\mathrm{c}}\right)$ versus the amplitude of the stress curves. (Continue on next page) 


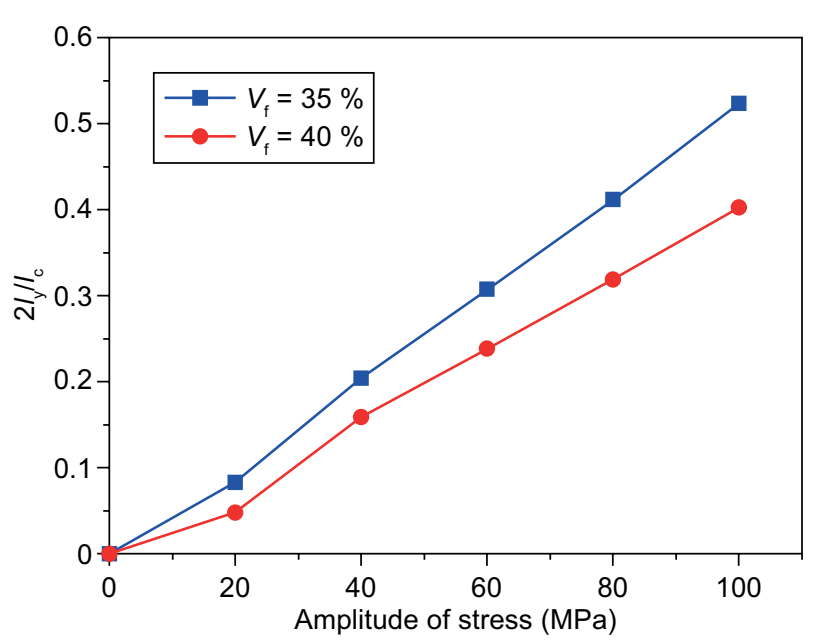

c)

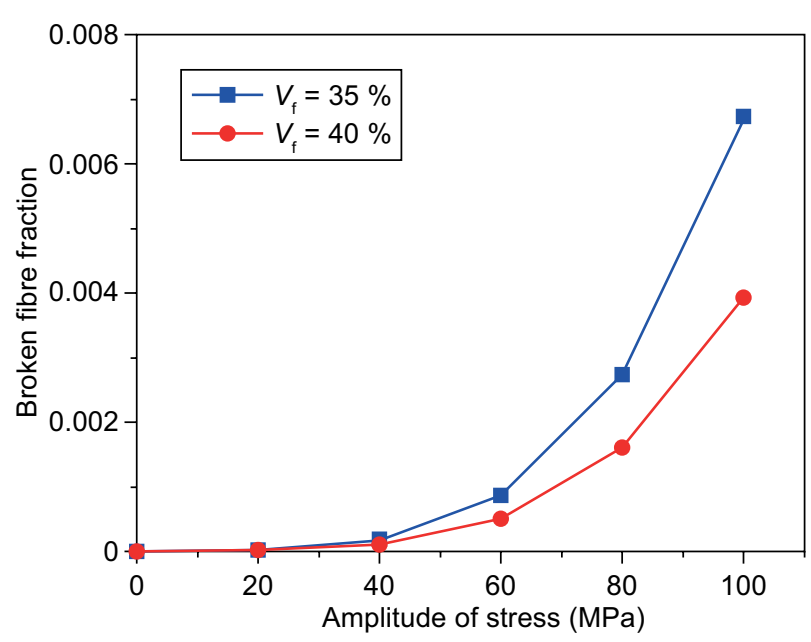

d)

Figure 1. The effect of the fibre volume (i.e., $V_{\mathrm{f}}=35$ and $\left.40 \%\right)$ on: $\mathrm{c}$ ) the interface slip length $\left(2 l_{\mathrm{y}} / l_{\mathrm{c}}\right)$ versus the amplitude of the stress curves; d) the broken fibre fraction versus the amplitude of the stress curves of the unidirectional SiC/CAS composite.

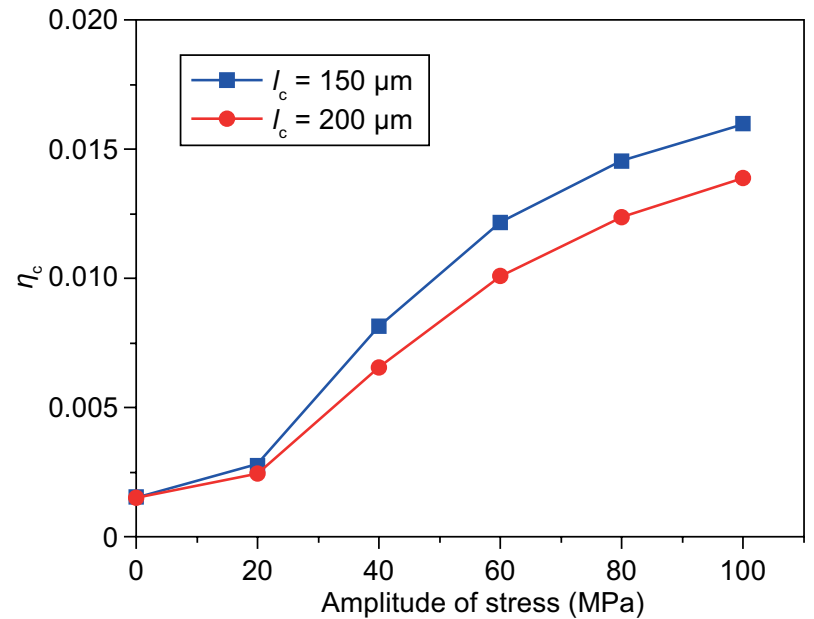

a)

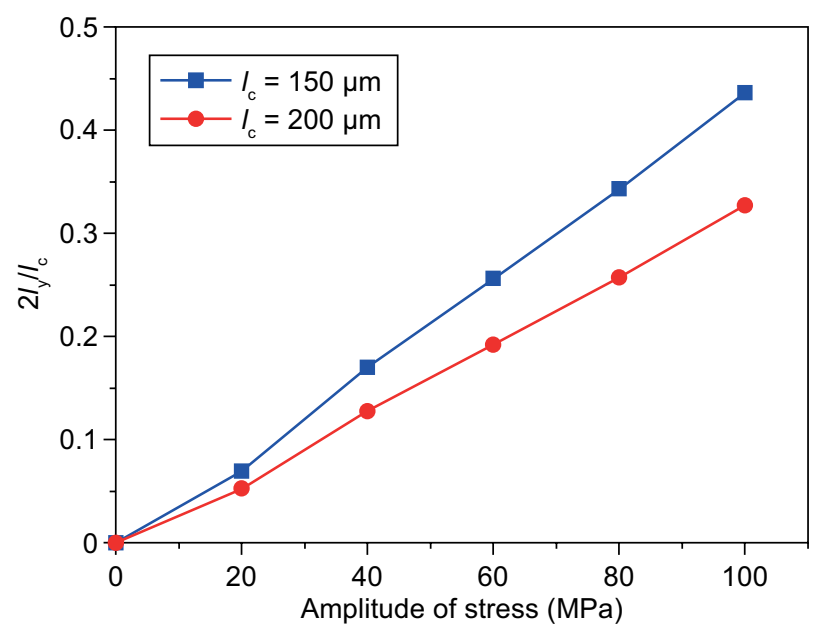

c)

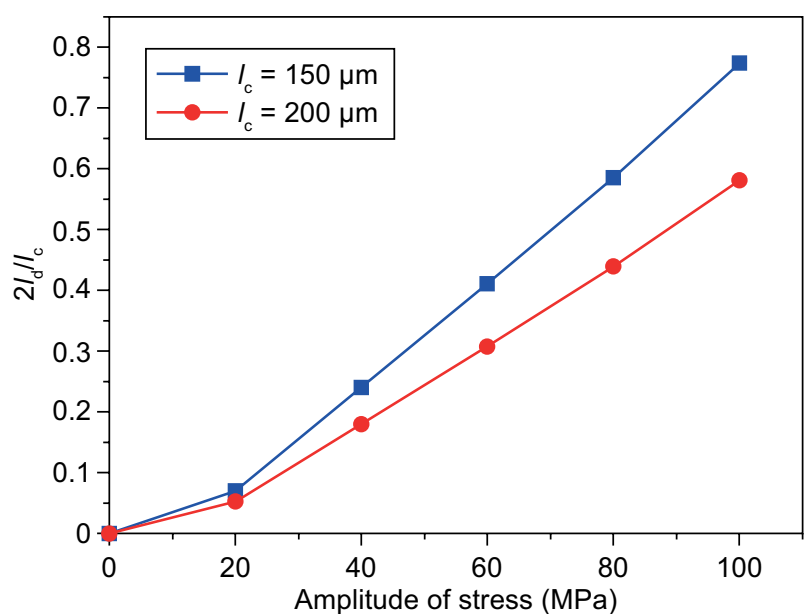

b)

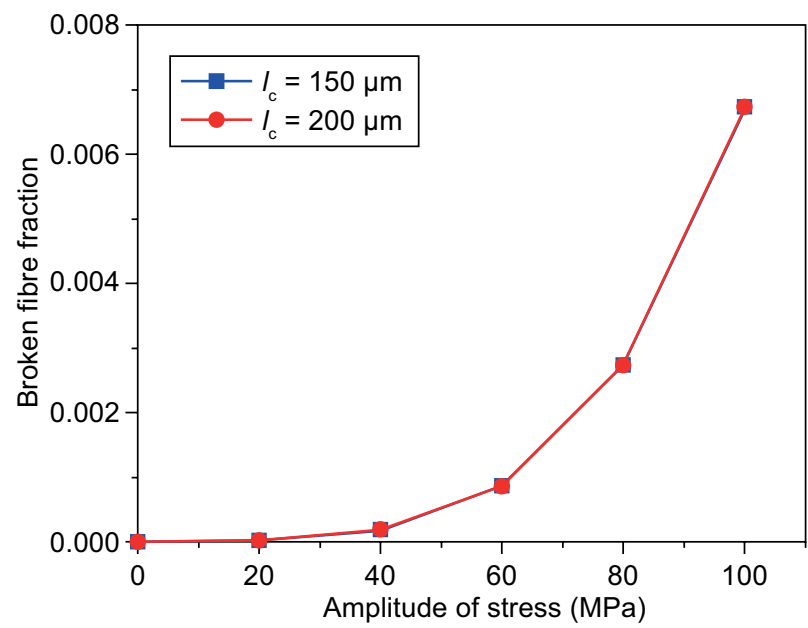

d)

Figure 2. The effect of the matrix crack spacing (i.e., $l_{\mathrm{c}}=150$ and $\left.200 \mu \mathrm{m}\right)$ on: a) the damping $\left(\eta_{\mathrm{c}}\right)$ versus the amplitude of the stress curves; $b)$ the interface debonding length $\left(2 l_{\mathrm{d}} / l_{\mathrm{c}}\right)$ versus the amplitude of the stress curves; $\left.\mathrm{c}\right)$ the interface slip length $\left(2 l_{\mathrm{y}} / l_{\mathrm{c}}\right)$ versus the amplitude of the stress curves; $d$ ) the broken fibre fraction versus the amplitude of the stress curves of the unidirectional $\mathrm{SiC} / \mathrm{CAS}$ composite. 
Effect of fibre volume on damping of CMCs

The effect of the fibre volume $\left(V_{\mathrm{f}}=35\right.$ and $\left.40 \%\right)$ on the damping of $\eta_{\mathrm{c}}$, the interface debonding length of $2 l_{\mathrm{d}} / l_{\mathrm{c}}$, the interface slip length of $2 l_{y} / l_{\mathrm{c}}$, and the broken fibre fraction versus the amplitude of the stress curves of unidirectional SiC/CAS composite is shown in Figure 1. When the fibre volume increases, the composite damping decreases, due to the decrease in the interface debonding and slip length and the broken fibre fraction.

When the fibre volume is $V_{\mathrm{f}}=35 \%$, the composite damping increases from $\eta_{\mathrm{c}}=0.00153$ at $\sigma=0$ to $\eta_{\mathrm{c}}=$ $=0.01735$ at $\sigma=100 \mathrm{MPa}$; the interface debonding length increases from $2 l_{\mathrm{d}} / l_{\mathrm{c}}=0$ at $\sigma=0$ to $2 l_{\mathrm{d}} / l_{\mathrm{c}}=0.92$ at $\sigma=100 \mathrm{MPa}$; the interface slip length increases from $2 l_{y} / l_{\mathrm{c}}=0$ at $\sigma=0$ to $2 l_{y} / l_{\mathrm{c}}=0.52$ at $\sigma=100 \mathrm{MPa}$; and the broken fibre fraction increases from $P=0$ at $\sigma=0$ to $P=0.0067$ at $\sigma=100 \mathrm{MPa}$.

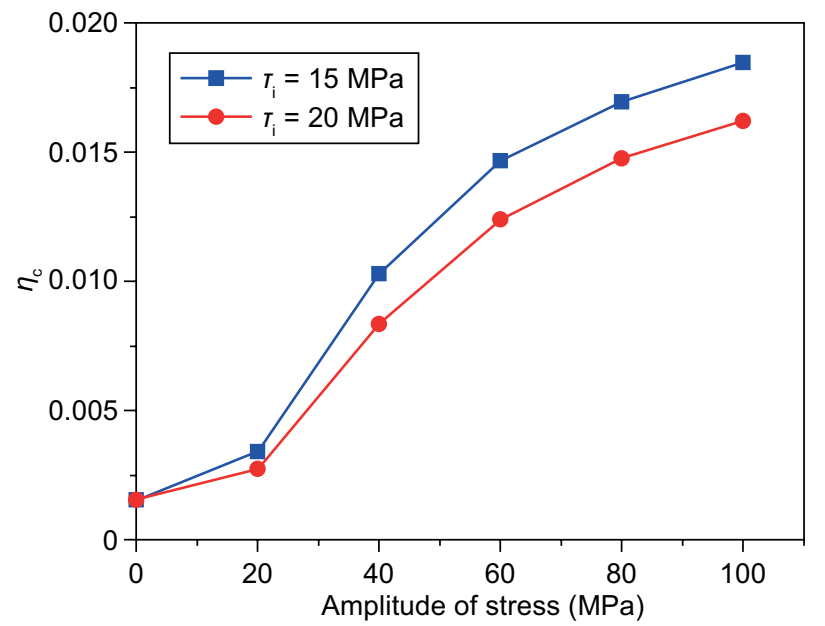

a)

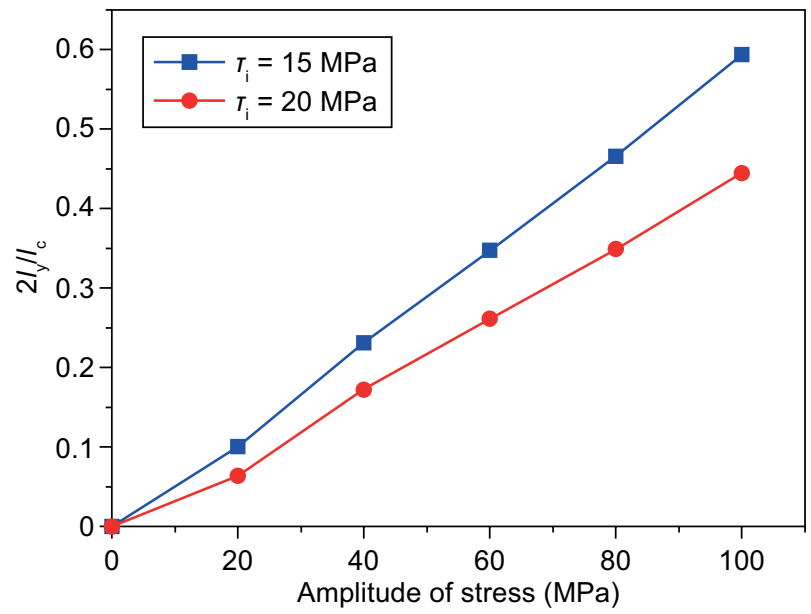

c)
When the fibre volume is $V_{\mathrm{f}}=40 \%$, the composite damping increases from $\eta_{\mathrm{c}}=0.0016$ at $\sigma=0$ to $\eta_{\mathrm{c}}=$ $=0.01351$ at $\sigma=100 \mathrm{MPa}$; the interface debonding length increases from $2 l_{\mathrm{d}} / l_{\mathrm{c}}=0$ at $\sigma=0$ to $2 l_{\mathrm{d}} / l_{\mathrm{c}}=0.69$ at $\sigma=100 \mathrm{MPa}$; the interface slip length increases from $2 l_{y} / l_{\mathrm{c}}=0$ at $\sigma=0$ to $2 l_{y} / l_{\mathrm{c}}=0.40$ at $\sigma=100 \mathrm{MPa}$; and the broken fibre fraction increases from $P=0$ at $\sigma=0$ to $P=0.0039$ at $\sigma=100 \mathrm{MPa}$.

\section{Effect of matrix crack spacing on damping of CMCs}

The effect of the matrix crack spacing $\left(l_{\mathrm{c}}=150\right.$ and $200 \mu \mathrm{m})$ on the damping of $\eta_{\mathrm{c}}$, the interface debonding length of $2 l_{\mathrm{d}} / l_{\mathrm{c}}$, the interface slip length of $2 l_{\mathrm{y}} / l_{\mathrm{c}}$, and the broken fibre fraction versus the amplitude of the stress curves of the unidirectional $\mathrm{SiC} / \mathrm{CAS}$ composite is shown in Figure 2. When the matrix crack spacing increases, the composite damping decreases, due to the decrease in the interface debonding and slip range.

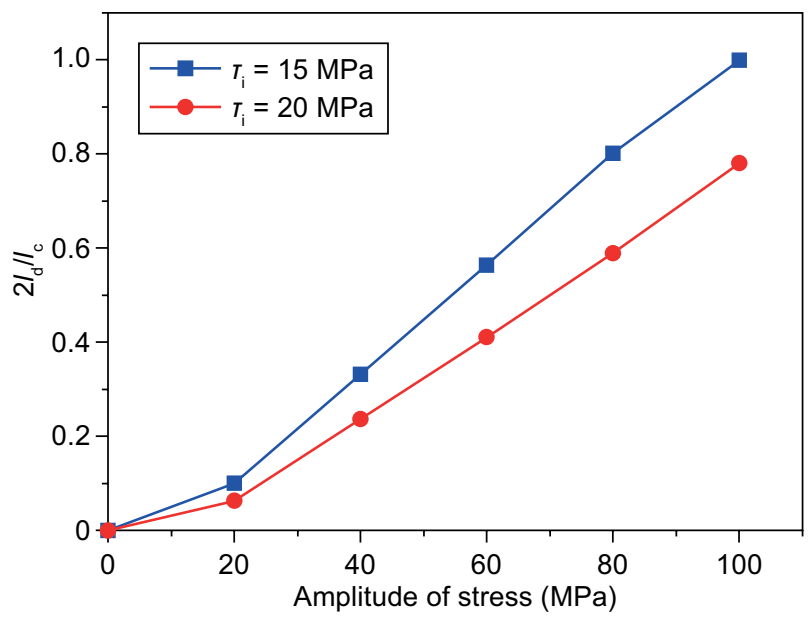

b)

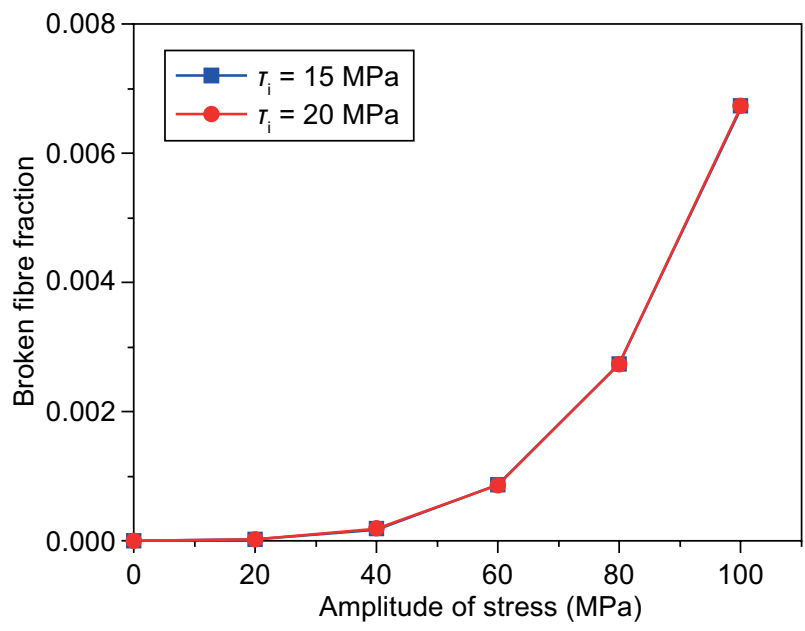

d)

Figure 3. The effect of the interface shear stress (i.e., $\tau_{i}=15$ and $20 \mathrm{MPa}$ ) on: a) the damping $\left(\eta_{\mathrm{c}}\right)$ versus the amplitude of the stress curves; $b)$ the interface debonding length $\left(2 l_{\mathrm{d}} / l_{\mathrm{c}}\right)$ versus the amplitude of the stress curves; $\left.\mathrm{c}\right)$ the interface slip length $\left(2 l_{\mathrm{y}} / l_{\mathrm{c}}\right)$ versus the amplitude of the stress curves; $d$ ) the broken fibre fraction versus the amplitude of the stress curves of the unidirectional $\mathrm{SiC} / \mathrm{CAS}$ composite. 
When the matrix crack spacing is $l_{\mathrm{c}}=150 \mu \mathrm{m}$, the composite damping increases from $\eta_{\mathrm{c}}=0.00153$ at $\sigma=0$ to $\eta_{\mathrm{c}}=0.016$ at $\sigma=100 \mathrm{MPa}$; the interface debonding length increases from $2 l_{\mathrm{d}} / l_{\mathrm{c}}=0$ at $\sigma=0$ to $2 l_{\mathrm{d}} / l_{\mathrm{c}}=0.77$ at $\sigma=100 \mathrm{MPa}$; the interface slip length increases from $2 l_{y} / l_{\mathrm{c}}=0$ at $\sigma=0$ to $2 l_{y} / l_{\mathrm{c}}=0.43$ at $\sigma=100 \mathrm{MPa}$; and the broken fibre fraction increases from $P=0$ at $\sigma=0$ to $P=0.00673$ at $\sigma=100 \mathrm{MPa}$.

When the matrix crack spacing is $l_{\mathrm{c}}=200 \mu \mathrm{m}$, the composite damping increases from $\eta_{\mathrm{c}}=0.00153$ at $\sigma=0$ to $\eta_{\mathrm{c}}=0.013$ at $\sigma=100 \mathrm{MPa}$; the interface debonding length increases from $2 l_{\mathrm{d}} / l_{\mathrm{c}}=0$ at $\sigma=0$ to $2 l_{\mathrm{d}} / l_{\mathrm{c}}=0.58$ at $\sigma=100 \mathrm{MPa}$; the interface slip length increases from $2 l_{y} / l_{\mathrm{c}}=0$ at $\sigma=0$ to $2 l_{y} / l_{\mathrm{c}}=0.327$ at $\sigma=100 \mathrm{MPa}$; and the broken fibre fraction increases from $P=0$ at $\sigma=0$ to $P=0.00673$ at $\sigma=100 \mathrm{MPa}$.
Effect of interface shear stress on damping of CMCs

The effect of the interface shear stress $\left(\tau_{\mathrm{i}}=15\right.$ and $20 \mathrm{MPa}$ ) on the damping of $\eta_{\mathrm{c}}$, the interface debonding length of $2 l_{\mathrm{d}} / l_{\mathrm{c}}$, the interface slip length of $2 l_{\mathrm{y}} / l_{\mathrm{c}}$, and the broken fibre fraction versus amplitude of the stress curves of the unidirectional $\mathrm{SiC} / \mathrm{CAS}$ composite is shown in Figure 3. When the interface shear stress increases, the composite damping decreases, due to the decrease in the interface debonding and slip length.

When the interface shear stress is $\tau_{\mathrm{i}}=15 \mathrm{MPa}$, the composite damping increases from $\eta_{\mathrm{c}}=0.00153$ at $\sigma=0$ to $\eta_{\mathrm{c}}=0.01847$ at $\sigma=100 \mathrm{MPa}$; the interface debonding length increases from $2 l_{\mathrm{d}} / l_{\mathrm{c}}=0$ at $\sigma=0$ to $2 l_{\mathrm{d}} / l_{\mathrm{c}}=1$ at $\sigma=$ $=100 \mathrm{MPa}$; the interface slip length increases from $2 l_{y} / l_{\mathrm{c}}=0$ at $\sigma=0$ to $2 l_{y} / l_{\mathrm{c}}=0.59$ at $\sigma=100 \mathrm{MPa}$; and the broken fibre fraction increases from $P=0$ at $\sigma=0$ to $P=0.00673$ at $\sigma=100 \mathrm{MPa}$.

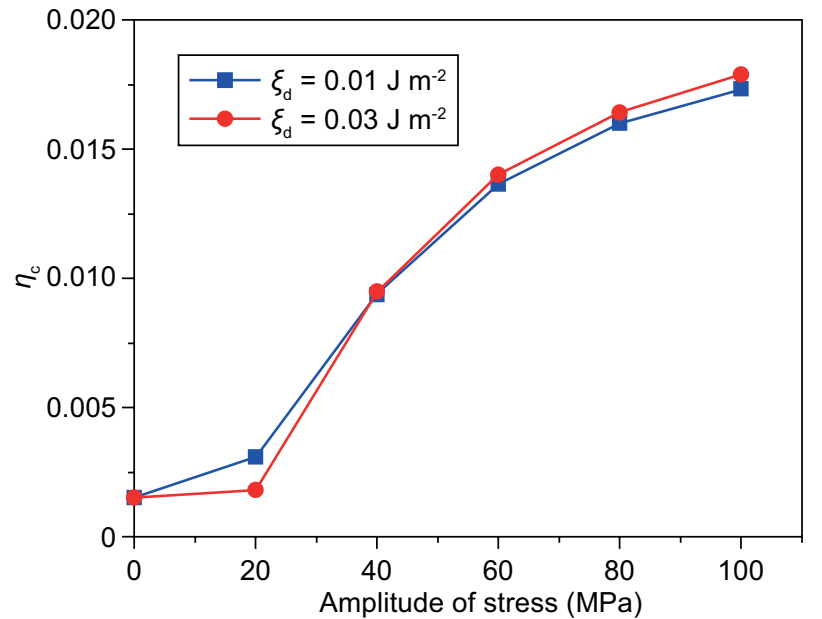

a)

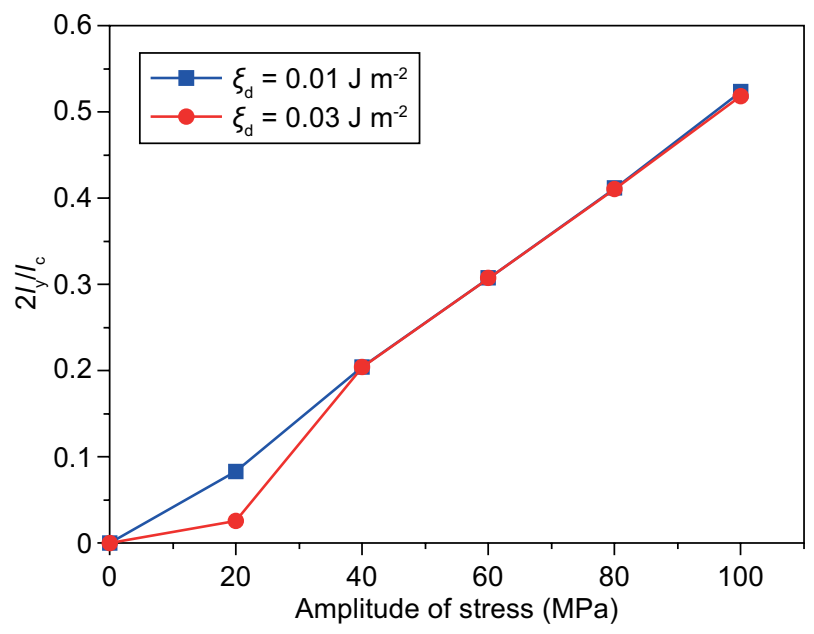

c)

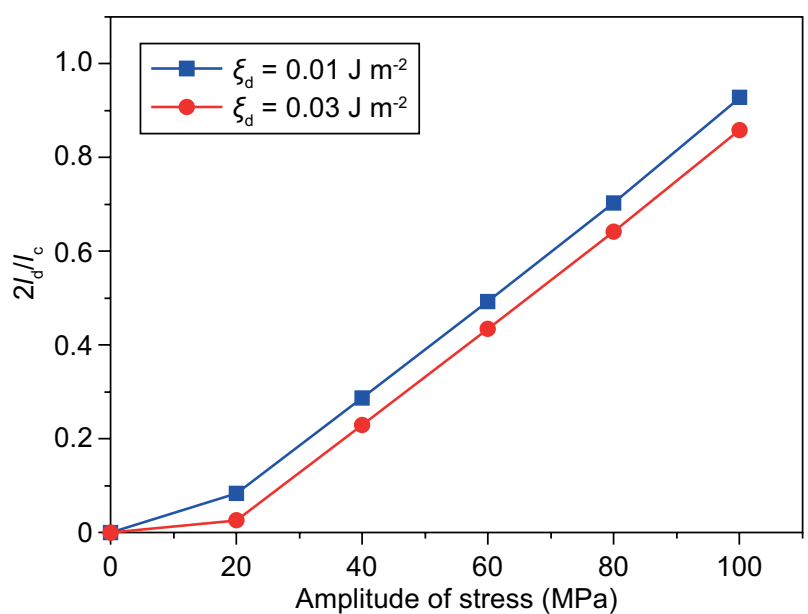

b)

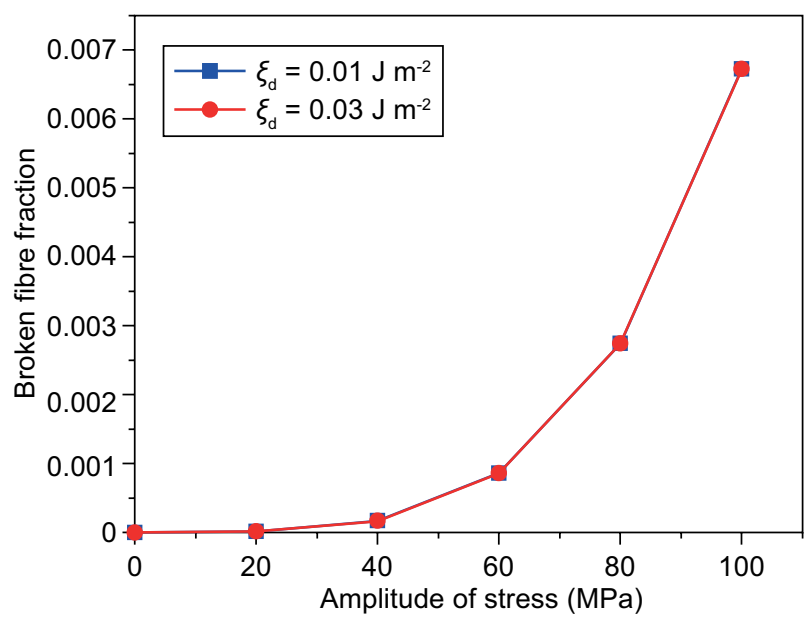

d)

Figure 4. The effect of the interface debonding energy (i.e., $\xi_{\mathrm{d}}=0.01$ and $0.03 \mathrm{~J} \cdot \mathrm{m}^{-2}$ ) on: a) the damping $\left(\eta_{\mathrm{c}}\right)$ versus the amplitude of the stress curves; $b)$ the interface debonding length $\left(2 l_{\mathrm{d}} l_{\mathrm{c}}\right)$ versus the amplitude of the stress curves; $\left.\mathrm{c}\right)$ the interface slip length $\left(2 l_{\mathrm{y}} / l_{\mathrm{c}}\right)$ versus the amplitude of the stress curves; $\left.d\right)$ the broken fibre fraction versus the amplitude of the stress curves of the unidirectional $\mathrm{SiC} / \mathrm{CAS}$ composite. 
When the interface shear stress is $\tau_{\mathrm{i}}=20 \mathrm{MPa}$, the composite damping increases from $\eta_{\mathrm{c}}=0.00153$ at $\sigma=0$ to $\eta_{\mathrm{c}}=0.01621$ at $\sigma=100 \mathrm{MPa}$; the interface debonding length increases from $2 l_{\mathrm{d}} / l_{\mathrm{c}}=0$ at $\sigma=0$ to $2 l_{\mathrm{d}} / l_{\mathrm{c}}=0.78$ at $\sigma=100 \mathrm{MPa}$; the interface slip length increases from $2 l_{y} / l_{\mathrm{c}}=0$ at $\sigma=0$ to $2 l_{y} / l_{\mathrm{c}}=0.44$ at $\sigma=100 \mathrm{MPa}$; and the broken fibre fraction increases from $P=0$ at $\sigma=0$ to $P=0.00673$ at $\sigma=100 \mathrm{MPa}$.

\section{Effect of interface debonding energy on damping of CMCs}

The effect of the interface debonding energy $\left(\xi_{\mathrm{d}}=0.01\right.$ and $\left.0.03 \mathrm{~J} \cdot \mathrm{m}^{-2}\right)$ on the damping of $\eta_{\mathrm{c}}$, the interface debonding length of $2 l_{\mathrm{d}} / l_{\mathrm{c}}$, the interface slip length of $2 l_{\mathrm{y}} / l_{\mathrm{c}}$, and the broken fibre fraction versus amplitude of the stress curves of the unidirectional $\mathrm{SiC} /$ CAS composite is shown in Figure 4. When the interface debonding energy increases, the composite damping decreases first and then increases, due to the decrease in the interface debonding length, and first the decrease and then the increase of the interface slip length.

When the interface debonding energy is $\xi_{\mathrm{d}}=$ $=0.01 \mathrm{~J} \cdot \mathrm{m}^{-2}$, the composite damping increases from $\eta_{\mathrm{c}}=0.00153$ at $\sigma=0$ to $\eta_{\mathrm{c}}=0.01735$ at $\sigma=100 \mathrm{MPa}$; the interface debonding length increases from $2 l_{\mathrm{d}} / l_{\mathrm{c}}=0$ at $\sigma=0$ to $2 l_{\mathrm{d}} / l_{\mathrm{c}}=0.927$ at $\sigma=100 \mathrm{MPa}$; the interface slip length increases from $2 l_{y} / l_{\mathrm{c}}=0$ at $\sigma=0$ to $2 l_{y} / l_{\mathrm{c}}=0.523$ at $\sigma=100 \mathrm{MPa}$; and the broken fibre fraction increases from $P=0$ at $\sigma=0$ to $P=0.00673$ at $\sigma=100 \mathrm{MPa}$.

When the interface debonding energy is $\xi_{\mathrm{d}}=$ $=0.03 \mathrm{~J} \cdot \mathrm{m}^{-2}$, the composite damping increases from $\eta_{\mathrm{c}}=0.00153$ at $\sigma=0$ to $\eta_{\mathrm{c}}=0.01789$ at $\sigma=100 \mathrm{MPa}$; the interface debonding length increases from $2 l_{\mathrm{d}} / l_{\mathrm{c}}=0$ at $\sigma=0$ to $2 l_{\mathrm{d}} l_{\mathrm{c}}=0.85$ at $\sigma=100 \mathrm{MPa}$; the interface slip length increases from $2 l_{y} / l_{\mathrm{c}}=0$ at $\sigma=0$ to $2 l_{y} / l_{\mathrm{c}}=0.517$ at $\sigma=100 \mathrm{MPa}$; and the broken fibre fraction increases from $P=0$ at $\sigma=0$ to $P=0.00673$ at $\sigma=100 \mathrm{MPa}$.

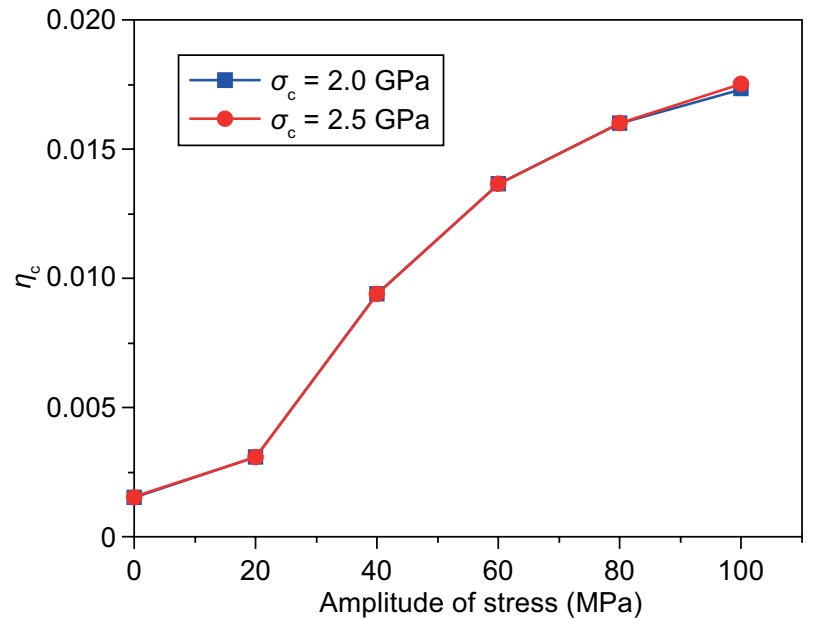

a)

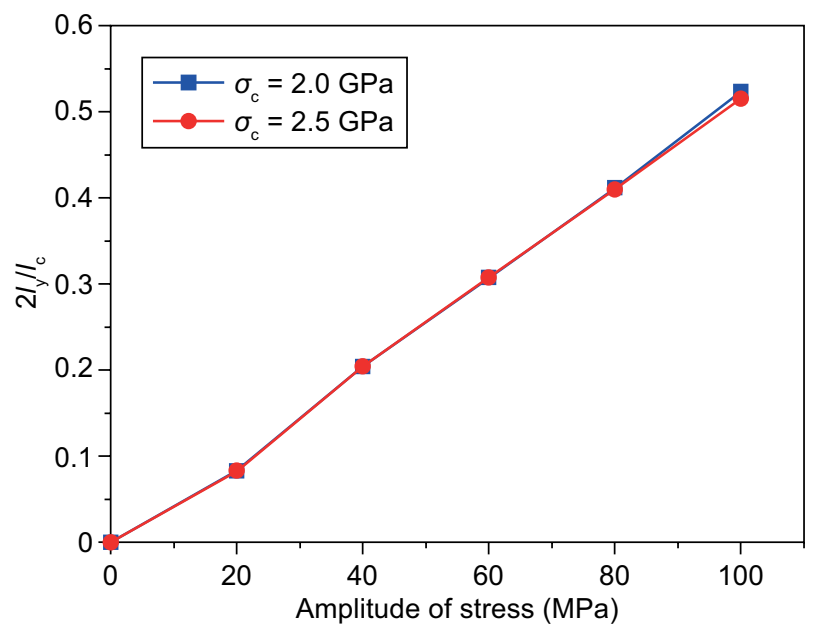

c)

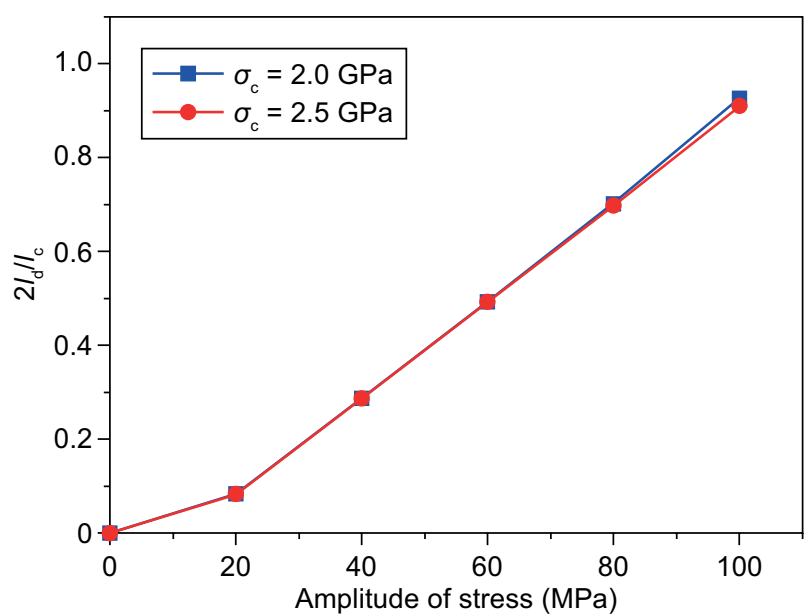

b)

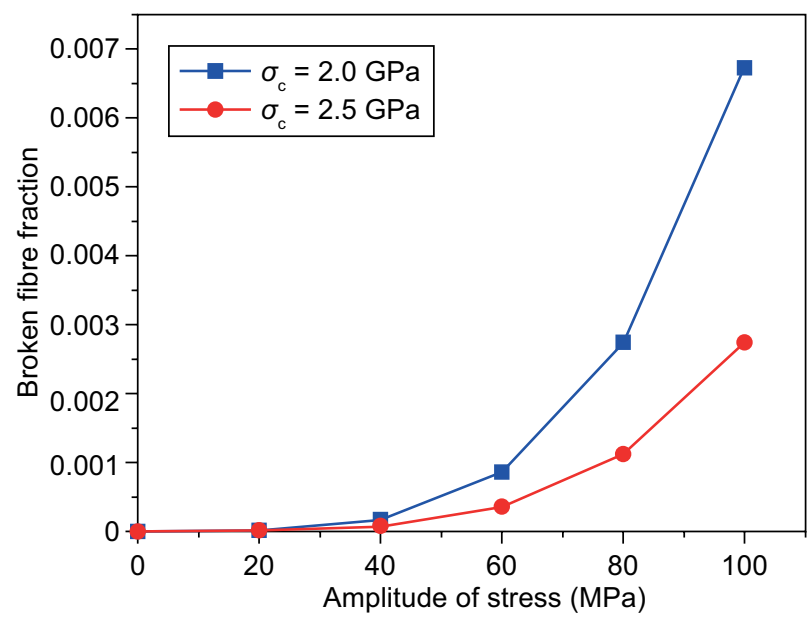

d)

Figure 5. The effect of the fibre strength (i.e., $\sigma_{\mathrm{c}}=2.0$ and $\left.2.5 \mathrm{GPa}\right)$ on: a) the damping $\left(\eta_{\mathrm{c}}\right)$ versus the amplitude of the stress curves; b) the interface debonding length $\left(2 l_{\mathrm{d}} / l_{\mathrm{c}}\right)$ versus the amplitude of the stress curves; $\left.\mathrm{c}\right)$ the interface slip length $\left(2 l_{\mathrm{y}} / l_{\mathrm{c}}\right)$ versus the amplitude of the stress curves; d) the broken fibre fraction versus the amplitude of the stress curves of the unidirectional $\mathrm{SiC} / \mathrm{CAS}$ composite. 
Effect of fibre strength on damping of CMCs

The effect of the fibre strength $\left(\sigma_{\mathrm{c}}=2.0\right.$ and $\left.2.5 \mathrm{GPa}\right)$ on the damping of $\eta_{\mathrm{c}}$, the interface debonding length of $2 l_{\mathrm{d}} / l_{\mathrm{c}}$, and the interface slip length of $2 l_{\mathrm{y}} / l_{\mathrm{c}}$, and the broken fibre fraction versus the amplitude of the stress curves of the unidirectional $\mathrm{SiC} / \mathrm{CAS}$ composite is shown in Figure 5. When the fibre strength increases, the composite damping increases, due to the decrease in the interface debonding length, interface slip length, and broken fibre fraction.

When the fibre strength is $\sigma_{\mathrm{c}}=2.0 \mathrm{GPa}$, the composite damping increases from $\eta_{\mathrm{c}}=0.00153$ at $\sigma=0$ to $\eta_{\mathrm{c}}=0.01735$ at $\sigma=100 \mathrm{MPa}$; the interface debonding length increases from $2 l_{\mathrm{d}} / l_{\mathrm{c}}=0$ at $\sigma=0$ to $2 l_{\mathrm{d}} / l_{\mathrm{c}}=0.927$ at $\sigma=100 \mathrm{MPa}$; the interface slip length increases from $2 l_{y} / l_{\mathrm{c}}=0$ at $\sigma=0$ to $2 l_{y} / l_{\mathrm{c}}=0.523$ at $\sigma=100 \mathrm{MPa}$; and the broken fibre fraction increases from $P=0$ at $\sigma=0$ to $P=0.00673$ at $\sigma=100 \mathrm{MPa}$.

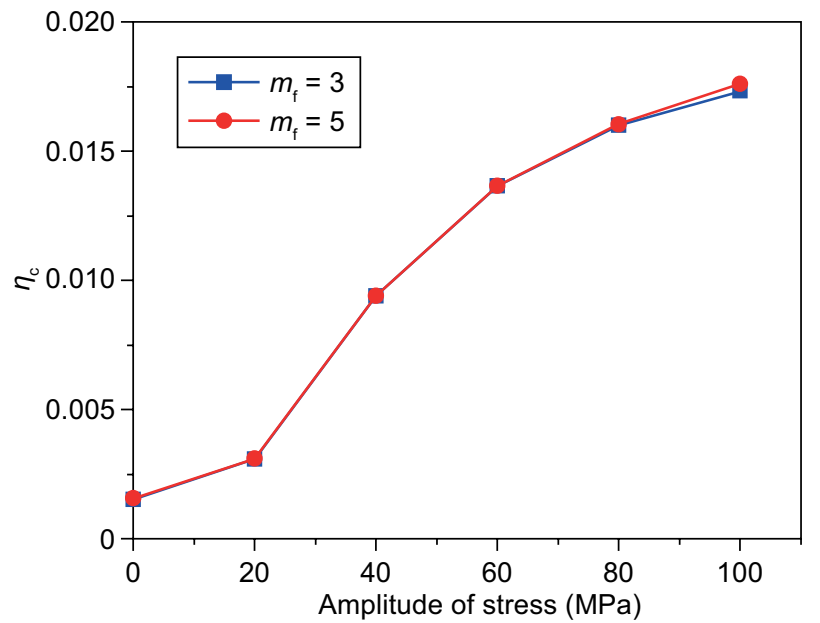

a)

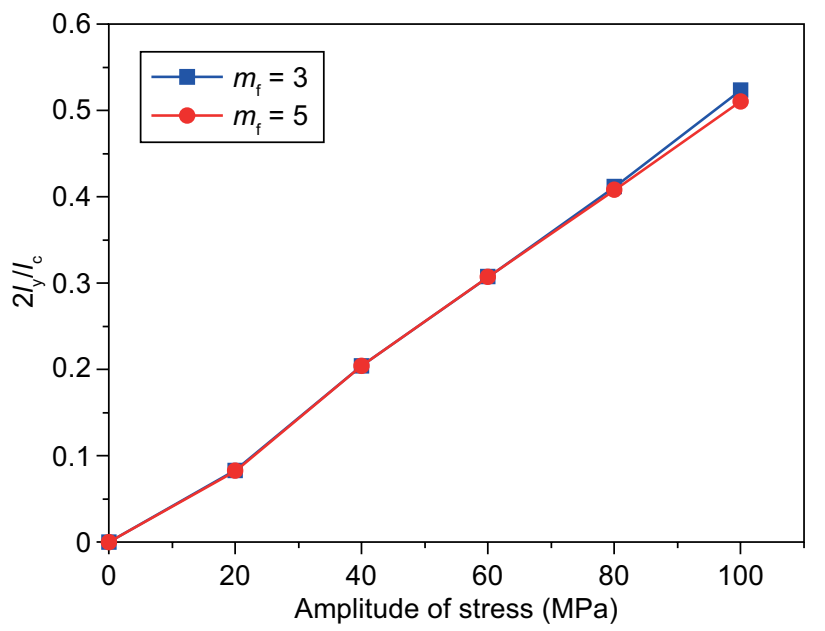

c)
When the fibre strength is $\sigma_{\mathrm{c}}=2.5 \mathrm{GPa}$, the composite damping increases from $\eta_{\mathrm{c}}=0.00153$ at $\sigma=0$ to $\eta_{\mathrm{c}}=0.01753$ at $\sigma=100 \mathrm{MPa}$; the interface debonding length increases from $2 l_{\mathrm{d}} / l_{\mathrm{c}}=0$ at $\sigma=0$ to $2 l_{\mathrm{d}} / l_{\mathrm{c}}=0.91$ at $\sigma=100 \mathrm{MPa}$; the interface slip length increases from $2 l_{y} / l_{\mathrm{c}}=0$ at $\sigma=0$ to $2 l_{y} / l_{\mathrm{c}}=0.514$ at $\sigma=100 \mathrm{MPa}$; and the broken fibre fraction increases from $P=0$ at $\sigma=0$ to $P=0.00274$ at $\sigma=100 \mathrm{MPa}$.

\section{Effect of fibre Weibull modulus on damping of CMCs}

The effect of fibre Weibull modulus ( $m_{\mathrm{f}}=3$ and 5) on the damping of $\eta_{\mathrm{c}}$, the interface debonding length of $2 l_{\mathrm{d}} / l_{\mathrm{c}}$, and the interface slip length of $2 l_{\mathrm{y}} / l_{\mathrm{c}}$, and the broken fibre fraction versus the amplitude of the stress curves of the unidirectional SiC/CAS composite is shown in Figure 6. When the fibre Weibull modulus increases, the

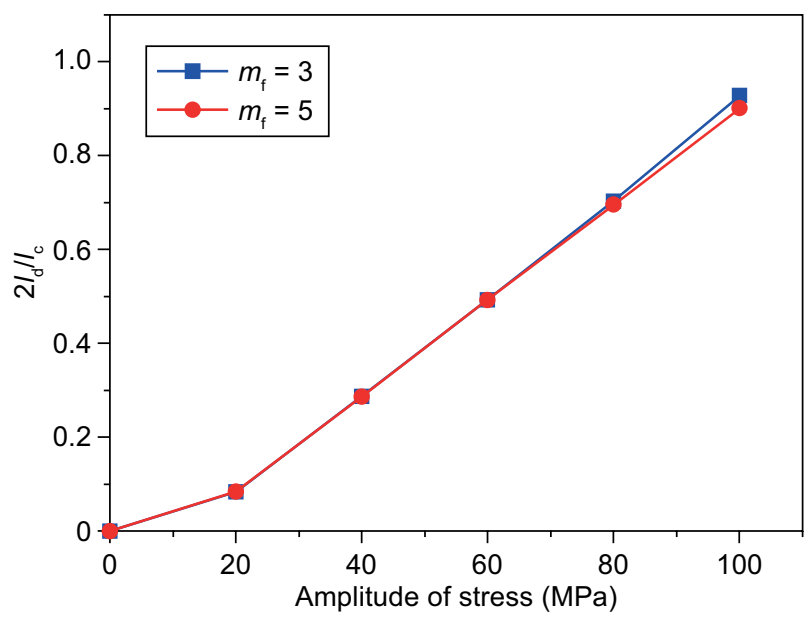

b)

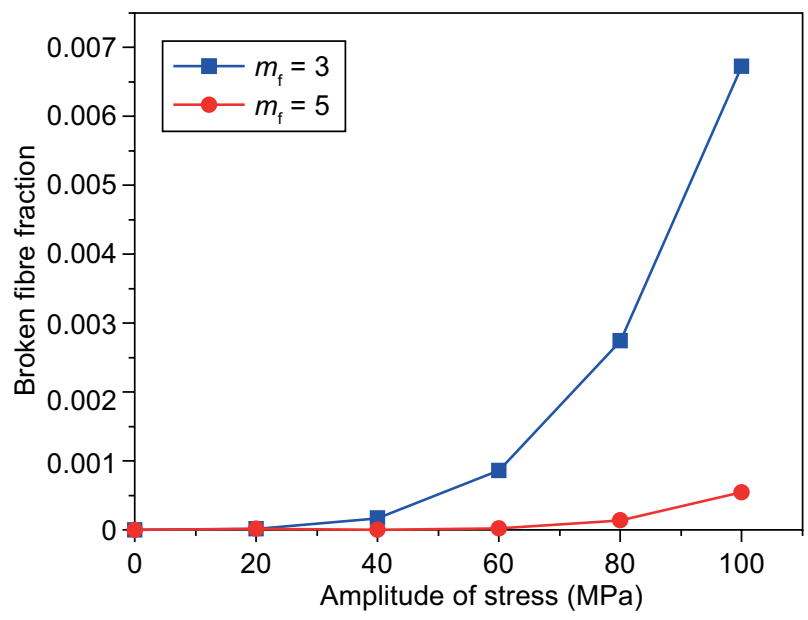

d)

Figure 6. The effect of the fibre Weibull modulus (i.e., $m_{\mathrm{f}}=3$ and 5) on: a) the damping $\left(\eta_{\mathrm{c}}\right)$ versus the amplitude of the stress curves; b) the interface debonding length $\left(2 l_{\mathrm{d}} / l_{\mathrm{c}}\right)$ versus the amplitude of the stress curves; $\left.\mathrm{c}\right)$ the interface slip length $\left(2 l_{\mathrm{y}} / l_{\mathrm{c}}\right)$ versus the amplitude of the stress curves; d) the broken fibre fraction versus the amplitude of the stress curves of the unidirectional $\mathrm{SiC} / \mathrm{CAS}$ composite. 
composite damping increases, due to the decrease in the interface debonding length, interface slip length, and broken fibre fraction.

When the fibre Weibull modulus is $m_{\mathrm{f}}=3$, the composite damping increases from $\eta_{\mathrm{c}}=0.00153$ at $\sigma=0$ to $\eta_{\mathrm{c}}=0.01735$ at $\sigma=100 \mathrm{MPa}$; the interface debonding length increases from $2 l_{\mathrm{d}} / l_{\mathrm{c}}=0$ at $\sigma=0$ to $2 l_{\mathrm{d}} / l_{\mathrm{c}}=0.927$ at $\sigma=100 \mathrm{MPa}$; the interface slip length increases from $2 l_{y} / l_{\mathrm{c}}=0$ at $\sigma=0$ to $2 l_{y} / l_{\mathrm{c}}=0.523$ at $\sigma=100 \mathrm{MPa}$; and the broken fibre fraction increases from $P=0$ at $\sigma=0$ to $P=0.00673$ at $\sigma=100 \mathrm{MPa}$.

When the fibre Weibull modulus is $m_{\mathrm{f}}=5$, the composite damping increases from $\eta_{\mathrm{c}}=0.00153$ at $\sigma=0$ to $\eta_{\mathrm{c}}=0.0176$ at $\sigma=100 \mathrm{MPa}$; the interface debonding length increases from $2 l_{\mathrm{d}} / l_{\mathrm{c}}=0$ at $\sigma=0$ to $2 l_{\mathrm{d}} / l_{\mathrm{c}}=0.9$ at $\sigma=100 \mathrm{MPa}$; the interface slip length increases from $2 l_{y} / l_{\mathrm{c}}=0$ at $\sigma=0$ to $2 l_{y} / l_{\mathrm{c}}=0.51$ at $\sigma=100 \mathrm{MPa}$; and the broken fibre fraction increases from $P=0$ at $\sigma=0$ to $P=0.0005$ at $\sigma=100 \mathrm{MPa}$.

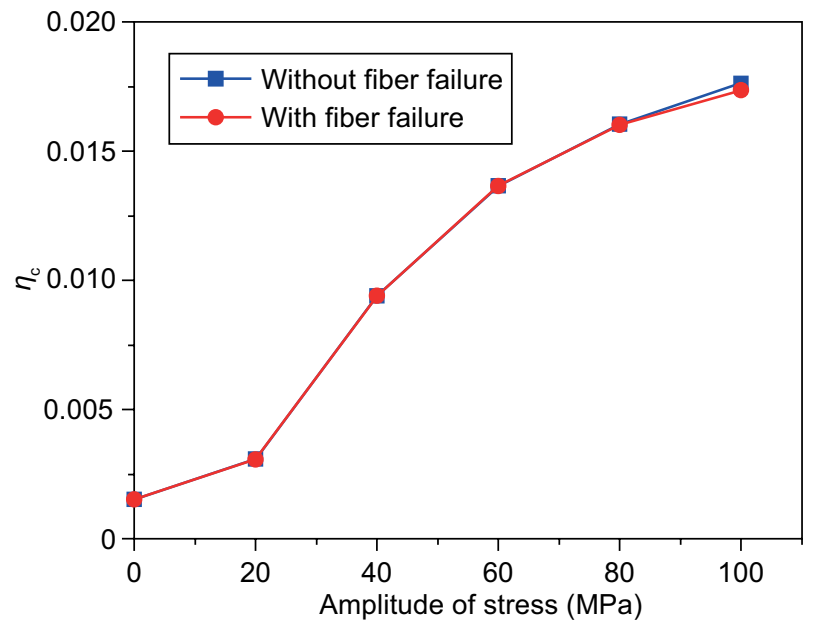

a)

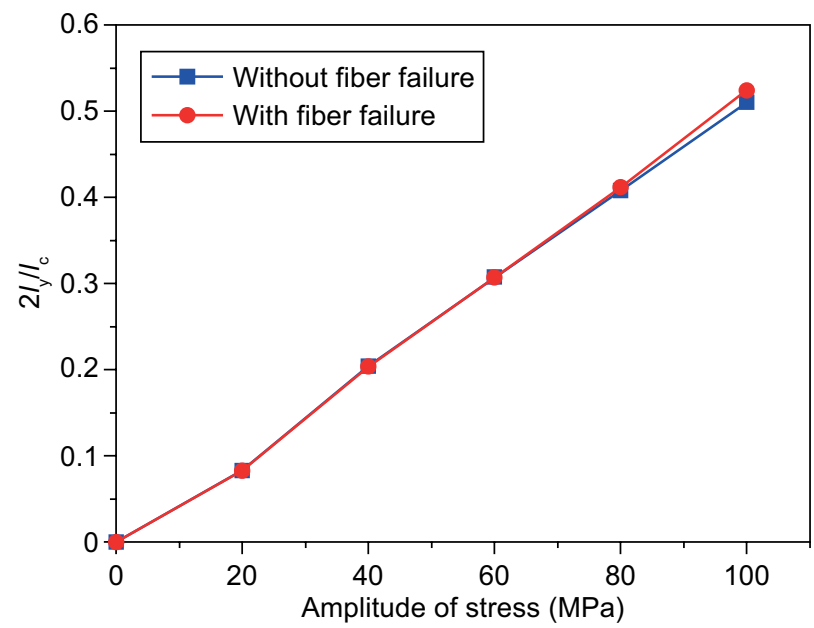

c)

\section{Comparisons of damping with and without considering fibre failure}

The comparisons of the damping of $\eta_{\mathrm{c}}$, the interface debonding length of $2 l_{\mathrm{d}} / l_{\mathrm{c}}$, and the interface slip length of $2 l_{\mathrm{y}} / l_{\mathrm{c}}$ with and without the fibre failure, and the broken fibre fraction versus the amplitude of the stress curves of the unidirectional $\mathrm{SiC} / \mathrm{CAS}$ composite are shown in Figure 7. Considering the fibre failure, the composite damping decreases, due to the increase in the fibre broken fraction.

When the fibre failure is not considered, the composite damping increases from $\eta_{\mathrm{c}}=0.00153$ at $\sigma=0$ to $\eta_{\mathrm{c}}=0.01762$ at $\sigma=100 \mathrm{MPa}$; the interface debonding length increases from $2 l_{\mathrm{d}} / l_{\mathrm{c}}=0$ at $\sigma=0$ to $2 l_{\mathrm{d}} / l_{\mathrm{c}}=0.89$ at $\sigma=100 \mathrm{MPa}$; the interface slip length increases from $2 l_{y} / l_{\mathrm{c}}=0$ at $\sigma=0$ to $2 l_{y} / l_{\mathrm{c}}=0.509$ at $\sigma=100 \mathrm{MPa}$.

When the fibre failure is considered, the composite damping increases from $\eta_{\mathrm{c}}=0.00153$ at $\sigma=0$ to $\eta_{\mathrm{c}}=$

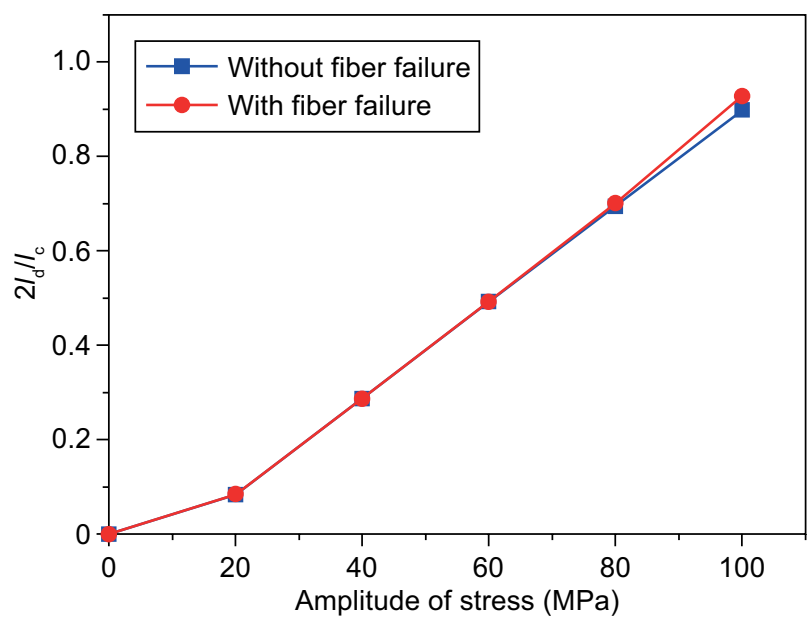

b)

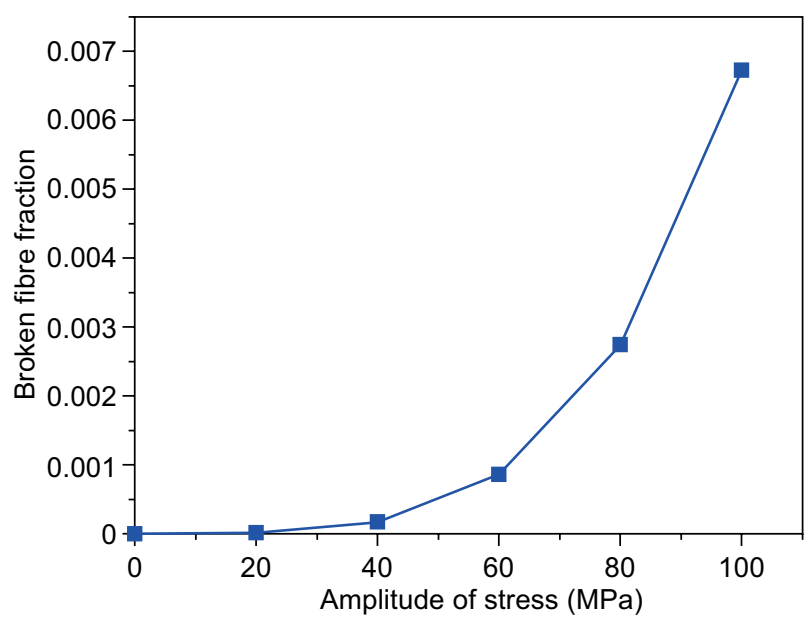

d)

Figure 7. The damping $\left(\eta_{\mathrm{c}}\right)$ versus the amplitude of the stress curves with and without the fibre failure (a); the interface debonding length $\left(2 l_{\mathrm{d}} / l_{\mathrm{c}}\right)$ versus the amplitude of the stress curves with and without the fibre failure (b); the interface slip length $\left(2 l_{\mathrm{y}} / l_{\mathrm{c}}\right)$ versus the amplitude of the stress curves with and without the fibre failure (c); and the broken fibre fraction versus the amplitude of the stress curves of the unidirectional $\mathrm{SiC} / \mathrm{CAS}$ composite (d). 
$=0.01735$ at $\sigma=100 \mathrm{MPa}$; the interface debonding length increases from $2 l_{\mathrm{d}} / l_{\mathrm{c}}=0$ at $\sigma=0$ to $2 l_{\mathrm{d}} / l_{\mathrm{c}}=0.927$ at $\sigma=100 \mathrm{MPa}$; the interface slip length increases from $2 l_{y} / l_{\mathrm{c}}=0$ at $\sigma=0$ to $2 l_{y} / l_{\mathrm{c}}=0.523$ at $\sigma=100 \mathrm{MPa}$; and the broken fibre fraction increases from $P=0$ at $\sigma=0$ to $P=0.00673$ at $\sigma=100 \mathrm{MPa}$.

\section{EXPERIMENTAL}

Wang et al. [9] investigated the damping behaviour of a $2 \mathrm{D}$ plain-weave CVI T300 ${ }^{\mathrm{TM}} \mathrm{C} / \mathrm{SiC}$ composite at different temperatures. The material properties of the $\mathrm{C} / \mathrm{SiC}$ composite are given by [9]: $E_{\mathrm{f}}=230 \mathrm{GPa}$, $E_{\mathrm{m}}=350 \mathrm{GPa}, V_{\mathrm{f}}=0.4, r_{\mathrm{f}}=3.5 \mu \mathrm{m}, \xi_{\mathrm{d}}=0.01 \mathrm{~J} \cdot \mathrm{m}^{-2}$, $l_{\mathrm{c}}=100 \mu \mathrm{m}, \eta_{\mathrm{f}}=0.002, \eta_{\mathrm{m}}=0.005, \alpha_{\mathrm{f}}=-0.7 \times 10^{-6} /{ }^{\circ} \mathrm{C}$, $\alpha_{\mathrm{m}}=4.6 \times 10^{-6} /{ }^{\circ} \mathrm{C}, \Delta T=-1000{ }^{\circ} \mathrm{C}, \sigma_{\mathrm{c}}=2.5 \mathrm{GPa}, m_{\mathrm{f}}=3$. The experimental and predicted damping of $\eta_{\mathrm{c}}$, the interface debonding length of $2 l_{\mathrm{d}} / l_{\mathrm{c}}$, and the interface slip length of $2 l_{\mathrm{y}} / l_{\mathrm{c}}$ versus the amplitude of the stress

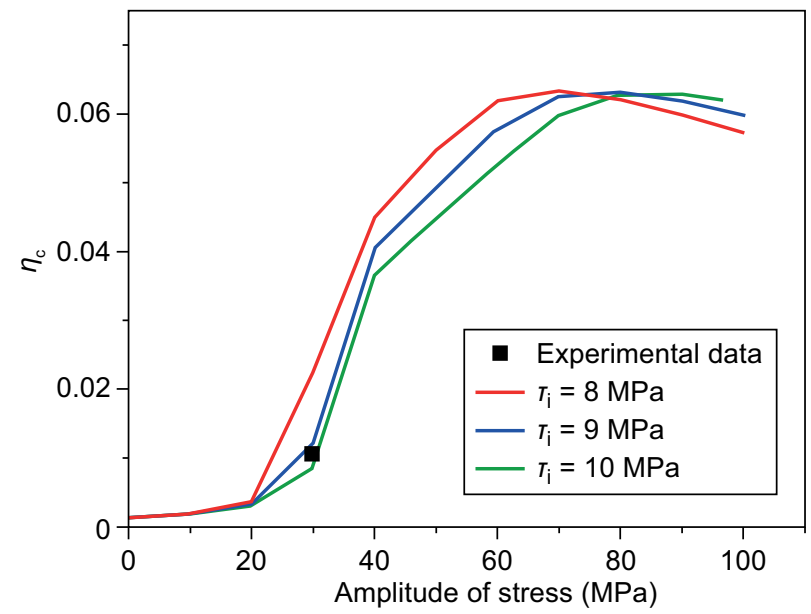

a)

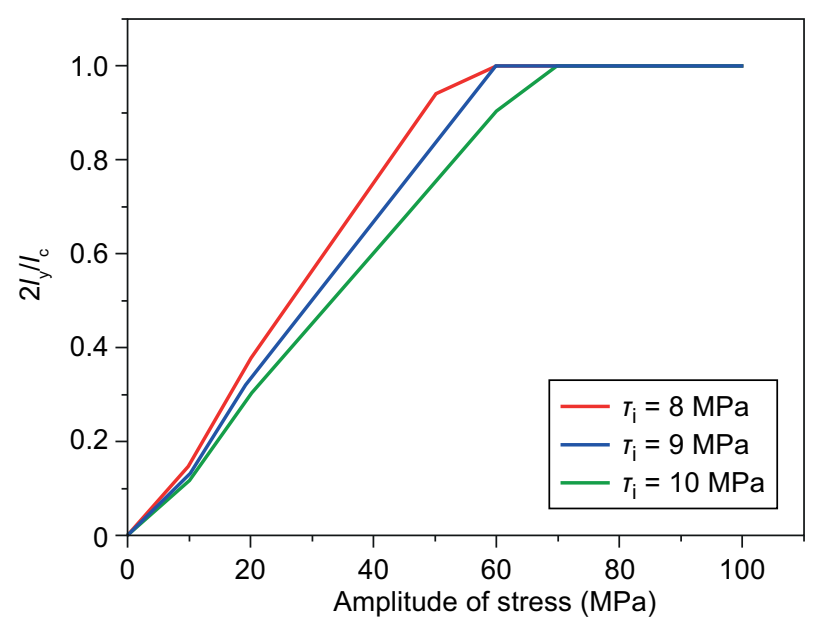

c) curves of the $\mathrm{C} / \mathrm{SiC}$ composite is shown in Figure 8 . The experimental damping of $\eta_{c}$ is 0.0106 at a temperature of $T=50{ }^{\circ} \mathrm{C}$, corresponding to an amplitude of the stress $\sigma=30 \mathrm{MPa}$, and an interface shear stress range of $\tau_{i}=9$ and $10 \mathrm{MPa}$, and an interface debonding length range of $2 l_{\mathrm{d}} / l_{\mathrm{c}}=0.716$ and 0.798 , and an interface slip length range of $2 l_{\mathrm{y}} / l_{\mathrm{c}}=0.45$ and 0.5 , and a broken fibre fraction of $P=0.0002$.

\section{CONCLUSIONS}

In this paper, the synergistic effects of the fibre debonding and fracturing on the vibration damping in fibre-reinforced CMCs is investigated. The relationships between the damping of the CMCs, the damping of the fibre and the matrix, the damping caused by the frictional slip between the fibre and the matrix, and the fibre debonding and fracturing are established. The effects of the fibre volume, matrix crack spacing,

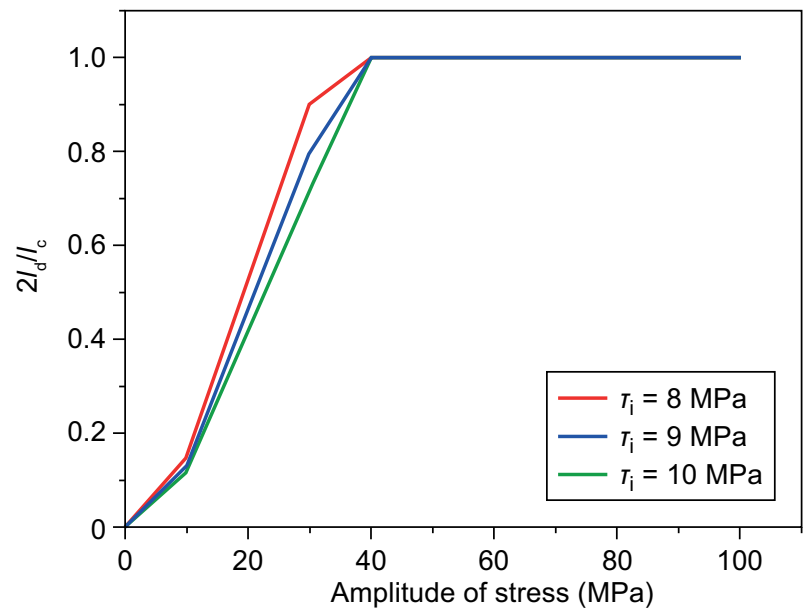

b)

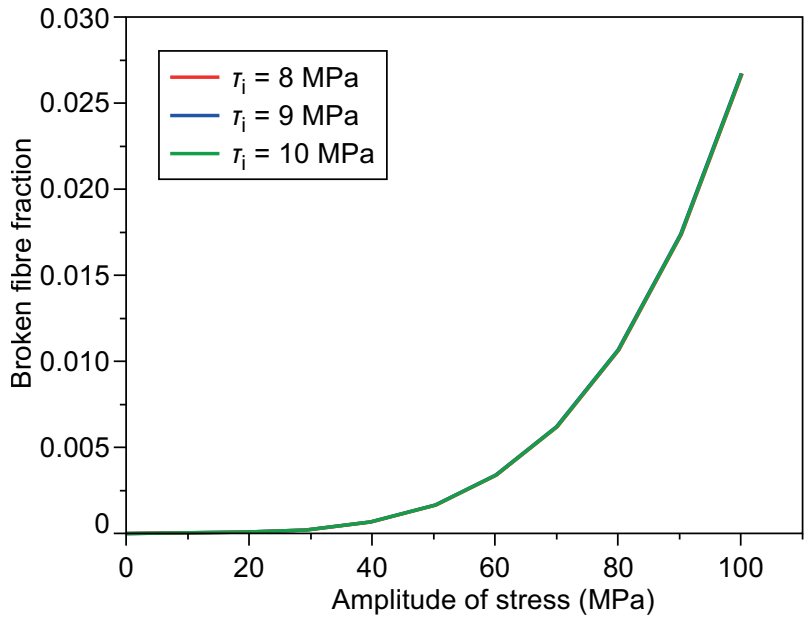

d)

Figure 8. The experimental and predicted damping $\left(\eta_{\mathrm{c}}\right)$ versus the amplitude of the stress curves (a); the interface debonding length $\left(2 l_{\mathrm{d}} / l_{\mathrm{c}}\right)$ versus the amplitude of the stress curves $(\mathrm{b})$; the interface slip length $\left(2 l_{\mathrm{y}} / l_{\mathrm{c}}\right)$ versus the amplitude of the stress curves $(\mathrm{c})$; and the broken fibre fraction versus the amplitude of the stress curves of the $\mathrm{C} / \mathrm{SiC}$ composite (d). 
interface shear stress, interface debonding energy, fibre strength and fibre Weibull modulus on the damping of the CMCs, the interface debonding and slip between the fibre and the matrix, and the fibre broken fraction are analysed. The damping of the unidirectional CMCs with and without considering the fibre failure is discussed. The experimental damping of a $2 \mathrm{D} \mathrm{C} / \mathrm{SiC}$ composite is predicted using the present analysis.

- When the fibre volume increases, the composite damping decreases, due to the decrease in the interface debonding and slip length and the broken fibre fraction.

- When the matrix crack spacing and interface shear stress increases, the composite damping decreases, due to the decrease in the interface debonding and slip range.

- When the interface debonding energy increases, the composite damping first decreases and then increases, due to the decrease in the interface debonding length, and the first decrease and then increase in the interface slip length.

- When the fibre strength and fibre Weibull modulus increase, the composite damping increases, due to the decrease in the interface debonding length, interface slip length, and broken fibre fraction.

- Considering the fibre failure, the composite damping decreases, due to the increase in the fibre broken fraction.

\section{Acknowledgements}

The work reported here is supported by the Fundamental Research Funds for the Central Universities (Grant No. NS2019038).

\section{REFERENCES}

1. Naslain R. (2004). Design, preparation and properties of non-oxide $\mathrm{CMCs}$ for application in engines and nuclear reactors: an overview. Composites Science and Technology, 64(2), 155-170. doi: 10.1016/S0266-3538(03)00230-6

2. Li L.B. (2020). Durability of Ceramic Matrix Composites. Elsevier.

3. Li L.B. (2019). Thermomechanical Fatigue of CeramicMatrix Composites. Wiley-VCH.

4. Li L.B. (2018). Damage, fracture and fatigue of ceramicmatrix composites. Springer Nature Singapore Pte Ltd. doi: 10.1007/978-981-13-1783-5

5. Min J.B., Harris D.L., Ting J.M. (2011): Advances in ceramic matrix composite blade damping characteristics for aerospace turbomachinery applications. In: $52^{\text {nd }} A I A A /$ ASME/ASCE/AHS/ASC Structures, Structural Dynamics and Materials Conference, Denver, Colorado. doi: 10.2514/ 6.2011-1784
6. Zhang J., Perez,R. J., Lavernia E. J. (1993): Documentation of damping capacity of metallic, ceramic and metal-matrix composite materials. Journal of Materials Science, 28(9), 2395-2404. doi: 10.1007/BF01151671

7. Birman V., Byrd L. W. (2002): Effect of matrix cracks on damping in unidirectional and cross-ply ceramic matrix composites. Journal of Composite Materials, 36(15), 18591877. doi: 10.1177/0021998302036015247

8. Sato S., Serizawa H., Araki H., Noda T., Kohyama A. (2003): Temperature dependence of internal friction and elastic modulus of $\mathrm{SiC} / \mathrm{SiC}$ composites. Journal of Alloys and Compounds, 355(1-2), 142-147. doi: 10.1016/S09258388(03)00252-4

9. Wang W., Cheng L.F., Zhang L.T., Xu Y.D., Wu W.M. (2006): Study on damping capacity of two dimensional carbon fiber reinforced silicon carbide $(2 \mathrm{D} \mathrm{C} / \mathrm{SiC}) \mathrm{com}$ posites. Journal of Solid Rocket Technology, 29, 455-459.

10. Zhang Q., Cheng L. F., Wang W., Wei X., Zhang L. T., Xu Y. D. (2007): Effects of interphase thickness on damping behavior of $2 \mathrm{D} \mathrm{C} / \mathrm{SiC}$ composites. Materials science forum, 546, 1531-1534. doi: 10.4028/www.scientific.net/ MSF.546-549.1531

11. Hong Z.L., Cheng L.F., Zhao C.N., Zhang L.T., Wang Y.G. (2013): Effect of oxidation on internal friction behavior of C/SC composites. Acta Materiae Compositae Sinica, 30, 93-100.

12. Li H.Q.(2019). Analysis of vibration and damage test of ceramic matrix composites structure. Master thesis, Nanchang Hongkong University, Nanchang China.

13. Li L.B. (2019): Temperature-dependent proportional limit stress of carbon fiber-reinforced silicon carbide ceramicmatrix composites. Ceramics-Silikáty, 63, 330-337. doi: $10.13168 /$ cs. 2019.0028

14. Li L.B. (2019): Modeling matrix multicracking development of fiber-reinforced ceramic-matrix composites considering fiber debonding. International Journal of Applied Ceramic Technology, 16(1), 97-107. doi: 10.1111/ijac.13068

15. Li L.B. (2019): Time-dependent matrix multi-fracture of $\mathrm{SiC} / \mathrm{SiC}$ ceramic-matrix composites considering interface oxidation. Ceramics-Silikáty, 63, 131-148. doi: 10.13168/ cs.2019.0005

16. Li L. B. (2018): Modeling the monotonic and cyclic tensile stress-strain behavior of $2 \mathrm{D}$ and $2.5 \mathrm{D}$ woven $\mathrm{C} / \mathrm{SiC}$ ceramic-matrix composites. Mechanics of Composite Materials, 54(2), 165-178. doi:10.1007/s11029-018-9729-5

17. Li L.B. (2020): Modeling tensile damage and fracture processes of fiber-reinforced ceramic-matrix composites under the effect of pre-exposure at elevated temperatures. Ceramics-Silikáty, 64, 50-62. doi: 10.13168/cs.2019.0048

18. Li L.B. (2018): Damage monitor and life prediction of carbon fiber-reinforced ceramic-matrix composites at room and elevated temperatures using hysteresis dissipated energy-based damage parameter. Composite Interfaces, 25(4), 335-356. doi: 10.1080/09276440.2018.1439621

19. Li L.B. (2019): Synergistic effects of frequency and temperature on fatigue hysteresis of cross-ply SiC/MAS composite under tension-tension loading. Ceramics-Silikáty, 63, 51-66. doi: 10.13168/cs.2018.0045 